\title{
Computer Programs
}

Abstracts of computer programs of interest to subscribers may be submitted to the Journal. Descriptions should not exceed 100 words. The equipment used and the name and affiliation of submitter should be added.

\section{Instructions to Authors}

Manuscripts in the areas of finance and quantitative analysis should be sent to the editor. Two copies should be enclosed and the authors' names should not appear on the manuscript to preserve anonymity. The manuscripts will then be forwarded to the appropriate associate editors. Manuscripts should be typed on $8 \frac{1}{2} \times 11$ paper and should be double-spaced. Mathematical notation should be kept as simple as possible. Where at all possible use common typewriter characters such as primes, slashes, asterisks, etc. Use power $\frac{1}{2}$ rather than square root.

Footnotes should be numbered consecutively and appear on the same page as the material to which they refer. Do not use footnotes on mathematical symbols. Reference material should be listed alphabetically on a separate sheet at the end of the manuscript.

The following subject matter areas are representative of the interest of the journal. The list is not all inclusive nor are the areas listed mutually exclusive.

Business Finance

Investments

Banking

Financial Institutions

Monetary Theory and Policy

Credit

Consumer Finance

Real Estate Finance

International Finance
Statistics

Operations Research

Management Science

Computers

Information Theory and Technology

Risk and Uncertainty Analysis

Decision Theory

Insurance

Financial Aspects of Non-Profit Organizations 